\title{
Male circumcision and prevalence of genital human papillomavirus infection in men: a multinational study
}

Ginesa Albero ${ }^{1,2,3}$, Luisa L Villa ${ }^{4}$, Eduardo Lazcano-Ponce ${ }^{5}$, William Fulp ${ }^{6}$, Mary R Papenfuss ${ }^{6}$, Alan G Nyitray ${ }^{6}$, Beibei Lư ${ }^{6}$, Xavier Castellsagué ${ }^{1,2}$, Martha Abrahamsen ${ }^{6}$, Danélle Smith ${ }^{6}$, F Xavier Bosch', Jorge Salmerón? Manuel Quiterio ${ }^{5}$ and Anna R Giuliano ${ }^{6^{*}}$

\begin{abstract}
Background: Accumulated evidence from epidemiological studies and more recently from randomized controlled trials suggests that male circumcision (MC) may substantially protect against genital HPV infection in men. The purpose of this study was to assess the association between MC and genital HPV infection in men in a large multinational study.
\end{abstract}

Methods: A total of 4072 healthy men ages 18-70 years were enrolled in a study conducted in Brazil, Mexico, and the United States. Enrollment samples combining exfoliated cells from the coronal sulcus, glans penis, shaft, and scrotum were analyzed for the presence and genotyping of HPV DNA by PCR and linear array methods. Prevalence ratios (PR) were used to estimate associations between MC and HPV detection adjusting for potential confounders.

Results: MC was not associated with overall prevalence of any HPV, oncogenic HPV types or unclassified HPV types. However, MC was negatively associated with non-oncogenic HPV infections (PR 0.85, 95\% confident interval: 0.76-0.95), in particular for HPV types 11, 40, 61, 71, and 81. HPV 16, 51, 62, and 84 were the most frequently identified genotypes regardless of MC status.

Conclusions: This study shows no overall association between MC and genital HPV infections in men, except for certain non-oncogenic HPV types for which a weak association was found. However, the lack of association with MC might be due to the lack of anatomic site specific HPV data, for example the glans penis, the area expected to be most likely protected by MC.

Keywords: Male circumcision, Genital, HPV, Non-oncogenic, Prevalence

\section{Background}

Genital human papillomavirus (HPV) infection is one of the most common sexually transmitted infections (STI) in the world [1]. Genital HPV prevalence in men has been reported to range from $2 \%$ to $93 \%$ among high-risk men such as HIV-positive males, male partners of women with HPV infection or abnormal cytology, and patients attending STI clinics and from $1 \%$ to $84 \%$ among all other groups [2]. Most observational studies have shown an inverse association between male circumcision (MC) and genital HPV infection [3-9]. Three randomized controlled

\footnotetext{
* Correspondence: anna.giuliano@moffitt.org

${ }^{6} \mathrm{H}$. Lee Moffitt Cancer Center and Research Institute, Tampa, FL 33612, USA Full list of author information is available at the end of the article
}

trials (RCT) in Africa have shown that MC substantially reduces HIV infection in men [10-12], and two of these have also found that $\mathrm{MC}$ reduced the prevalence of high risk HPV infections [13,14]. A recent systematic review and meta-analysis showed an inverse association between MC and genital HPV prevalence in men [15]. Another review reported a strong protective effect of $\mathrm{MC}$ against penile cancer [16]. However, the association reported between MC and genital HPV infection has not been consistent across all studies [17-21]. We previously published interim data in support of an inverse association between MC and genital HPV detection in the first 1158 men enrolled in the HPV in Men study (HIM Study) [6]. In the present analysis, we re-evaluated the association between

\section{Biomed Central}


MC and HPV detection, type distribution and possible effect modification by sexual behavior among all men enrolled in the HIM Study.

\section{Methods}

\section{Study population}

The HIM Study is a multinational longitudinal study of HPV in men. Between June 2005 and September 2009, 4072 men who completed both the pre-enrollment and the enrollment visits formed the study population for the present analysis. Details of the cohort have been previously described [6,22]. In brief, men were eligible for participation if they were aged 18-70 years, residents of Tampa, Florida, Cuernavaca, Mexico, or São Paulo, Brazil, had no prior anal or penile cancer or genital warts, and no current diagnosis of STIs. Men were recruited from several population sources. In Brazil, men were recruited from the general population, public health clinic attendees, and partners of women participating in a natural history study of HPV. Men visiting the clinic for STI symptoms or treatment were excluded. In Mexico, men were recruited through a large health plan, from factories, and the military. In the United States, men were recruited from the University of South Florida and the Tampa metropolitan area. Men who were eligible to participate reviewed a written informed consent with a trained study team member. Consenting participants underwent a clinical examination at 10 visits: a preenrollment visit, an enrollment visit approximately 2 weeks later, and 8 additional visits after enrollment that occurred every 6 months over a period of 4 years. Before study initiation, the human subjects committees of the University of South Florida, the Centro de Referencia e Tratamento de Doencas Sexualmente Transmissiveis e AIDS, Brazil, and the National Institute of Public Health of Mexico approved the research protocol.

At the enrollment visit, men completed an 88-item Computer-Assisted Self-Interview (CASI) that has been demonstrated to elicit reliable responses [23]. The CASI collected information about participant socio-demographic characteristics, tobacco consumption, and sexual behaviors. After the interview, a clinician examined each participant for signs of STIs and assessed circumcision status. Participants with full or partial circumcision were considered to be circumcised.

\section{Penile and scrotal sampling}

Three different saline pre-wetted Dacron (Digene, Gaithersburg, MD, USA) swabs were obtained from the coronal sulcus/glans penis, penile shaft, and scrotum, and placed in $450 \mu \mathrm{l}$ of Specimen Transportation Medium, and combined into one sample before DNA extraction. Among uncircumcised men, the foreskin was sampled at the time of collection of the coronal sulcus/glans penis sample. We have previously shown the validity and high sampling reproducibility of these three anatomical sites in the assessment of HPV DNA status [24,25]. All HPV samples were stored at $-80^{\circ} \mathrm{C}$ until PCR analysis and genotyping were performed.

\section{HPV analyses}

DNA was extracted with the Media Kit (QIAGen, Valencia, CA, USA) by a robotic system according to the manufacturer's instructions. DNA was stored at $4^{\circ} \mathrm{C}$ until use. HPV testing of the combined DNA extract was undertaken by use of PCR for amplification of a fragment of the HPV L1 gene. Specimens were tested for the presence of HPV by amplification of $30 \mathrm{ng}$ of DNA with the PGMY09/11 L1 consensus primer system [26]. HPV genotyping was done with the linear array method on all samples irrespective of the HPV PCR result (Roche Molecular Diagnostics, Alameda, CA, USA) [27].

Before genotyping, amplification products were run on $2 \%$ agarose gels to visualise a $450 \mathrm{bp}$ band corresponding to HPV amplification for identification of samples that might have an HPV type other than the 37 types analyzed in the genotyping assay. Samples in which HPV was amplified on PCR, but did not hybridise with a specific HPV type during genotyping were categorized as unclassified infections. The 13 HPV types that were classified as oncogenic were: $16,18,31,33,35,39,45,51$, $52,56,58,59$ and 68 . The non-oncogenic HPV types were: $6,11,26,40,42,53,54,55,61,62,64,66,67,69$, 70, 71, 72, 73, 81, 82, 83, 84, IS39, and CP6108 [28]. Samples were considered valid if they were HPV positive by PCR or by genotyping, or $\beta$-globin positive, regardless of HPV result. Valid samples were available from 3969 of 4072 participants.

\section{Statistical analysis}

The present analysis included four classifications of HPV detection. A participant was considered positive for "Any HPV type" if he tested HPV positive by PCR or by genotyping for any HPV genotype. The category of "Oncogenic HPV" included men who were positive for only oncogenic genotypes as well as those who were positive for both oncogenic and non-oncogenic types. The "Non-oncogenic HPV" category consisted of those participants who tested positive for non-oncogenic HPV genotypes only. The "Unclassified HPV infections" included men with samples that tested positive for HPV by PCR but negative for all of the 37 genotypes tested.

Differences in the distribution of socio-demographic characteristics, tobacco consumption and sexual behavior characteristics by circumcision status were compared using Pearson's chi-square test. Prevalence ratios (PRs) and 95\% confidence intervals (CIs) were estimated using univariate and multivariable modified Poisson regression with robust variance $[29,30]$. Separate models 
were constructed for each HPV outcome (i.e., any HPV, oncogenic HPV, non-oncogenic HPV, and unclassified HPV infections). Uncircumcised men served as the reference group for circumcision status, and men who had no detectable HPV (HPV negative on both PCR and genotyping assays) served as the comparison group in the modeling of each HPV outcome. All risk factor variables and potential confounders were initially considered using multivariable modified Poisson regression modeling. For variable selection, all variables in a model were included, and then individually eliminated if not statistically significant at the 0.05 level. This variable selection procedure was performed for the four HPV outcomes. Variables that were not statistically significant in any of the models were excluded from the final multivariable models.

To explore whether sexual behavior modified the association between MC and HPV detection, we stratified the analysis by lifetime number of female sexual partners, and formally tested the interaction between lifetime number of female sexual partners and MC by including in the model both the interaction and the main-effect terms. Statistical analyses were conducted using SAS software, version 9.2 (SAS Institute Inc., Cary, NC) and R 2.13.0 (R Development Core Team). All statistical tests were two sided with a significance threshold of 0.05 .

\section{Results}

Socio-demographic characteristics of the 3969 participants by circumcision status are summarized in Table 1 . The majority of men were uncircumcised (64.1\%). The mean age of participants was 30.9 years among circumcised men and 33.4 years among uncircumcised men. Most circumcised men were recruited from the United States (72.1\%) and among uncircumcised men, 46.8\% were recruited from Brazil, and $43.8 \%$ from Mexico. Among circumcised men, $66.2 \%$ were positive for any HPV, 29.4\% for oncogenic HPV, 19.7\% for non-oncogenic HPV only, and $17.1 \%$ for unclassified HPV infections. Among uncircumcised men, $67.0 \%$ were positive for any HPV, 30.0\% for oncogenic HPV, 24.3\% for non-oncogenic HPV, and $12.7 \%$ for unclassified HPV infections. Statistically significant differences by circumcision status were observed for age, country of residence, race, marital status, education, sexual orientation, number of female sexual partners in the past 3-6 months, male anal sexual partners in the past 3 months, self-reported STI history, and HPV status.

The univariate and multivariable associations of MC with each of the four pre-defined individual outcomes (i.e., any HPV, oncogenic HPV, non-oncogenic HPV, and unclassified HPV infections) are presented in Table 2. No association was observed between MC and HPV detection for any HPV or oncogenic HPV in either the univariate or the multivariable analyses. However, MC was significantly negatively associated with non-oncogenic HPV detection in both the univariate (PR 0.87, 95\% CI $0.78-0.97$ ) and the multivariable models (PR $0.85,95 \% \mathrm{CI}$ 0.76-0.95). MC was significantly positively associated with prevalence of unclassified HPV infections in the univariate analysis (PR 1.21, 95\% CI 1.05-1.39) but not in the final multivariable analysis (PR 1.07, 95\% CI 0.92-1.24).

As shown in Table 3, the association between MC and non-oncogenic HPV differed significantly by the number of lifetime female sexual partners (test of interaction, $\mathrm{P}=0.006$ ). Thus, $\mathrm{MC}$ was associated with a reduced prevalence of non-oncogenic HPV infections among men reporting 1 to 4 lifetime female sexual partners in both models (univariate PR $0.62,95 \%$ CI $0.45-0.83$; multivariable PR $0.59,95 \%$ CI $0.42-0.83)$. In contrast, no association with $\mathrm{MC}$ was observed among men reporting 5 or more lifetime female sexual partners for nononcogenic HPV. Although in the univariate analysis MC was associated with a statistically significant increased risk of unclassified HPV infections (PR 1.24, 95\% CI 1.01-1.51) among men reporting 1-4 partners, the PR was reduced to 1.03 (95\% CI $0.82-1.28$ ) in the final multivariable analysis. No associations with $\mathrm{MC}$ were observed among men reporting 5 or more lifetime female sexual partners for any HPV, oncogenic HPV, or unclassified HPV infections. The test of interaction between MC and lifetime female sexual partners was not statistically significant for the other three outcomes (i.e., any HPV type, oncogenic HPV, and unclassified HPV infections). Moreover, no association was found between MC and detection of HPV by country of residence (data not shown).

Table 4 presents the type-specific HPV distribution by circumcision status. HPV 16, 51, 62, 84, and CP6108 were the most frequently identified genotypes regardless of MC status. Concerning individual HPV genotypes, MC was associated with significantly reduced risk of nononcogenic HPV types 11 (PR 0.46, 95\% CI 0.24-0.88), 40 (PR 0.30, 95\% CI 0.15-0.61), 61 (PR 0.50, 95\% CI 0.360.71), 71 (PR 0.17, 95\% CI 0.07-0.43), and 81 (PR 0.55, 95\% CI 0.36-0.82). MC was not associated with prevalence of any of the individual thirteen oncogenic HPV types detected.

\section{Discussion}

Our study found that MC was not associated with overall prevalence of genital HPV for any HPV, oncogenic HPV infections, or unclassified HPV infections. However, MC was negatively associated with non-oncogenic HPV infections. After adjustment for potential confounders and stratification by lifetime number of female sexual partners, the protective association between MC and non-oncogenic HPV detection was particularly evident in men reporting 1 to 4 lifetime female sexual partners. The lack of an effect of MC among men with a 
Table 1 Socio-demographic characteristics of study participants by circumcision status $\mathbf{N}=3969$

\begin{tabular}{|c|c|c|c|c|c|}
\hline & \multicolumn{4}{|c|}{ Circumcision } & \multirow[t]{4}{*}{ P-value } \\
\hline & & & & & \\
\hline & \multicolumn{2}{|c|}{$N=2545(64.1 \%)$} & \multicolumn{2}{|c|}{$N=1424(35.9 \%)$} & \\
\hline & $\mathrm{N}$ & $\%$ & $\mathrm{~N}$ & $\%$ & \\
\hline Age & & & & & $<0.001$ \\
\hline Mean (SD) & & & & & \\
\hline $18-30$ & 1115 & 43.8 & 822 & 57.7 & \\
\hline $31-44$ & 1119 & 44.0 & 406 & 28.5 & \\
\hline $45-70$ & 311 & 12.2 & 196 & 13.8 & \\
\hline Country of residence & & & & & $<0.001$ \\
\hline US & 241 & 9.5 & 1027 & 72.1 & \\
\hline Brazil & 1190 & 46.8 & 197 & 13.8 & \\
\hline Mexico & 1114 & 43.8 & 200 & 14.0 & \\
\hline Race & & & & & $<0.001$ \\
\hline White & 877 & 35.1 & 889 & 63.1 & \\
\hline Black & 397 & 15.9 & 218 & 15.5 & \\
\hline Asian/Pacific Islander & 65 & 2.6 & 46 & 3.3 & \\
\hline Mexican & 1020 & 40.8 & 183 & 13.0 & \\
\hline Other (American Indian, Mixed) & 141 & 5.6 & 73 & 5.2 & \\
\hline Unknown & 45 & & 15 & & \\
\hline Marital status & & & & & $<0.001$ \\
\hline Single & 946 & 37.3 & 838 & 58.9 & \\
\hline Married & 1035 & 40.8 & 322 & 12.7 & \\
\hline Cohabiting & 373 & 14.7 & 104 & 4.1 & \\
\hline Divorced/Separated/Widowed & 183 & 7.2 & 158 & 11.1 & \\
\hline Unknown & 8 & & 2 & & \\
\hline Education & & & & & $<0.001$ \\
\hline$<12$ Years & 750 & 29.6 & 133 & 9.3 & \\
\hline Completed 12 Years & 774 & 30.6 & 292 & 20.5 & \\
\hline 13-15 Years & 377 & 14.9 & 623 & 43.8 & \\
\hline Completed 16 Years & 497 & 19.6 & 273 & 19.2 & \\
\hline$\geq 17$ Years & 135 & 5.3 & 102 & 7.2 & \\
\hline Unknown & 12 & & 1 & & \\
\hline Current smoker & & & & & 0.054 \\
\hline No & 1916 & 75.4 & 1112 & 78.2 & \\
\hline Yes & 624 & 24.6 & 310 & 21.8 & \\
\hline Unknown & 5 & & 2 & & \\
\hline Sexual orientation & & & & & $<0.001$ \\
\hline MSW & 2092 & 82.5 & 1245 & 87.7 & \\
\hline MSWM & 161 & 6.4 & 54 & 3.8 & \\
\hline MSM & 132 & 5.2 & 41 & 2.9 & \\
\hline No sex & 150 & 5.9 & 79 & 5.6 & \\
\hline Unknown & 10 & & 5 & & \\
\hline
\end{tabular}


Table 1 Socio-demographic characteristics of study participants by circumcision status $\mathbf{N}=3969$ (Continued)

Lifetime female sexual partners
Median (SD)
$0-1$
$2-9$
$10-19$
$20-49$
$50+$
Unknown
Female sexual partners in past 3-6 months
Mean (SD)
0
1
2
$3+$

Unknown

Male anal sexual partners in past 3 months

$$
\text { Mean (SD) }
$$

$$
1
$$$$
2
$$$$
3+
$$

Unknown

Diagnosis of STIs, ever

No

Yes

Unknown

HPV status

Negative

Oncogenic HPV

Non-oncogenic HPV

Unclassified HPV

HPV multiple infections

$$
\begin{aligned}
& \text { 2+ HPV types } \\
& 1 \text { HPV type }
\end{aligned}
$$

Negative
$6(2055.1)$

440
1040
416
354
124
171

$1.4(2.4)$

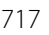

940

349

326

213

2341
75
31
73
25

$0.3(3.3)$

30.7
40.3
15.0
14.0

329
668
163
196
68

68

0.002

$$
0.1(1.0)
$$

92.9
3.0
1.2
2.9

$0.1(1.0)$
1363
25
16
20
0

95.7
1.8
1.1
1.4

NOTE. SD, standard deviation; US, the United States; MSW, men who have sex with women; MSWM, men who have sex with women and men; MSM, men who have sex with men; STI, sexually transmitted infections. Numbers in bold correspond to $P$ values $<0.05$.

greater number of lifetime sexual partners might be explained by immunity to HPV acquired over time by men who were repeatedly exposed to HPV infections [6]. Other studies have observed a plateau in risk for HPV detection despite increasing number of lifetime sexual partners $[3,6]$. However, in another analysis of the HIM Study, anti-HPV 16 serum antibody status at enrollment was not associated with the risk of a subsequent genital HPV 16 infection [31].
A preliminary analysis of the HIM study that included the first 1158 men who completed both the preenrollment and the enrollment visits, showed that MC was negatively associated with the detection of both non-oncogenic and oncogenic HPV types [6]. However, after increasing the sample size to 3969 men in this analysis, the association was only found for non-oncogenic HPV types after adjusting for potential confounders. Three other studies have reported statistically significant 
Table 2 Association between male circumcision and genital HPV detection in men

\begin{tabular}{|c|c|c|c|c|c|c|c|}
\hline \multicolumn{2}{|c|}{$\begin{array}{c}\text { Any HPV } \\
(n=3969)\end{array}$} & \multicolumn{2}{|c|}{$\begin{array}{c}\text { Oncogenic HPV } \\
(n=2503)\end{array}$} & \multicolumn{2}{|c|}{$\begin{array}{c}\text { Non-Oncogenic HPV } \\
(n=2219)\end{array}$} & \multicolumn{2}{|c|}{$\begin{array}{c}\text { Unclassified HPV } \\
(n=1889)\end{array}$} \\
\hline Univariate & Multivariable $^{1}$ & Univariate & Multivariable $^{1}$ & Univariate & Multivariable $^{1}$ & Univariate & Multivariable \\
\hline PR $(95 \% \mathrm{Cl})$ & PR $(95 \%$ Cl) & PR $(95 \% \mathrm{Cl})$ & PR $(95 \% \mathrm{Cl})$ & PR $(95 \% \mathrm{Cl})$ & PR $(95 \% \mathrm{Cl})$ & PR $(95 \% \mathrm{Cl})$ & PR $(95 \% \mathrm{Cl})$ \\
\hline
\end{tabular}

Circumcision

\begin{tabular}{|c|c|c|c|c|c|c|c|c|}
\hline No & 1.0 & 1.0 & 1.0 & 1.0 & 1.0 & 1.0 & 1.0 & 1.0 \\
\hline es & $0.99(0.94-1.04)$ & $0.96(0.91-1.01)$ & $0.98(0.90-1.07)$ & $0.95(0.87-1.03)$ & $0.87(0.78-0.97)$ & $0.85(0.76-0.95)$ & $1.21(1.05-1.39)$ & $1.07(0$. \\
\hline
\end{tabular}

NOTE. $P R$, prevalence ratio; $C l$, confidence interval. Numbers in bold correspond to statistically significant point estimates.

${ }^{1}$ Adjusted for race, marital status, lifetime female sexual partners, female sexual partners in past 3-6 months and male anal sexual partners in the past 3 months.

associations between $\mathrm{MC}$ and detection of non-oncogenic HPV types [5,14,32]. One MC RCT conducted in South Africa observed significantly lower prevalence of both oncogenic and non-oncogenic HPV types in urethral swab samples among circumcised men than uncircumcised men $[13,32]$. In another clinical trial in Uganda, the prevalence of both oncogenic and non-oncogenic HPV types using samples of the coronal sulcus/glans penis was lower among circumcised men than uncircumcised men [14]. Further, a study conducted among men attending a public
STI clinic, found that MC was associated with reduced risk for both oncogenic and non-oncogenic HPV types using samples of the coronal sulcus/glans penis [5]. However, results from three other studies did not support a protective role of MC on genital non-oncogenic HPV infection $[3,19,20]$.

The study of the effects of MC on genital HPV infections poses inherent complexities. Inconsistency of results across studies may be due to the genital site selected for HPV sampling or by the procedure used to collect exfoliated

Table 3 Association between MC and genital HPV detection in men by lifetime number of female partners

\begin{tabular}{|c|c|c|c|c|}
\hline & \multirow{4}{*}{$\mathrm{N}$} & \multicolumn{3}{|c|}{ Circumcision } \\
\hline & & \multirow[t]{3}{*}{ No } & \multicolumn{2}{|c|}{ Yes } \\
\hline & & & Univariate & Multivariable $^{1}$ \\
\hline & & & PR $(95 \% \mathrm{Cl})$ & PR $(95 \% \mathrm{Cl})$ \\
\hline \multicolumn{5}{|l|}{ Any HPV } \\
\hline Lifetime number of female partners & & & & $P=0.146^{2}$ \\
\hline $1-4$ & 1099 & 1.00 & $0.97(0.87-1.08)$ & $0.92(0.81-1.03)$ \\
\hline $5-12$ & 1183 & 1.00 & $0.98(0.91-1.07)$ & $0.96(0.88-1.05)$ \\
\hline $13+$ & 1083 & 1.00 & $1.03(0.97-1.10)$ & $1.03(0.96-1.10)$ \\
\hline \multicolumn{5}{|l|}{ Oncogenic HPV } \\
\hline Lifetime number of female partners & & & & $P=0.204^{2}$ \\
\hline $1-4$ & 667 & 1.00 & $0.93(0.73-1.19)$ & $0.96(0.73-1.26)$ \\
\hline $5-12$ & 726 & 1.00 & $0.96(0.82-1.12)$ & $0.92(0.77-1.09)$ \\
\hline $13+$ & 697 & 1.00 & $1.06(0.95-1.18)$ & $1.06(0.95-1.19)$ \\
\hline \multicolumn{5}{|l|}{ Non-Oncogenic HPV } \\
\hline Lifetime number of female partners & & & & $P=0.006^{2}$ \\
\hline $1-4$ & 647 & 1.00 & $0.62(0.45-0.83)$ & $0.59(0.42-0.83)$ \\
\hline $5-12$ & 668 & 1.00 & $0.89(0.74-1.07)$ & $0.88(0.72-1.08)$ \\
\hline $13+$ & 542 & 1.00 & $1.03(0.88-1.20)$ & $1.03(0.88-1.21)$ \\
\hline \multicolumn{5}{|l|}{ Unclassified HPV } \\
\hline Lifetime number of female partners & & & & $P=0.952^{2}$ \\
\hline $1-4$ & 717 & 1.00 & $1.24(1.01-1.51)$ & $1.03(0.82-1.28)^{3}$ \\
\hline $5-12$ & 527 & 1.00 & $1.25(0.96-1.61)$ & $1.15(0.86-1.53)^{3}$ \\
\hline $13+$ & 330 & 1.00 & $1.19(0.83-1.71)$ & $1.10(0.74-1.62)^{3}$ \\
\hline
\end{tabular}

NOTE. $P R$, prevalence ratio; $C l$, confidence interval. Numbers in bold correspond to statistically significant point estimates.

${ }^{1}$ Adjusted for race, marital status, female sexual partners in past 3-6 months and male anal sexual partners in the past 3 months.

${ }^{2}$ Test for interaction between MC and lifetime number of female partners.

${ }^{3}$ Adjusted for race, marital status, and male anal sexual partners in the past 3 months. 
Table 4 Genital type-specific HPV distribution in men by circumcision status

\begin{tabular}{|c|c|c|c|c|c|c|}
\hline \multirow[t]{3}{*}{ HPV } & \multicolumn{4}{|c|}{ Circumcision } & \multirow{3}{*}{$\begin{array}{c}\mathrm{N} \\
\text { total }\end{array}$} & \multirow[t]{3}{*}{ PR $(95 \% \mathrm{Cl})$} \\
\hline & \multicolumn{2}{|c|}{ No } & \multicolumn{2}{|c|}{ Yes } & & \\
\hline & $\mathbf{N}$ & $\%$ & $\mathbf{N}$ & $\%$ & & \\
\hline \multicolumn{7}{|c|}{ Oncogenic } \\
\hline 16 & 190 & 7.5 & 117 & 8.2 & 307 & $1.10(0.88-1.37)$ \\
\hline 18 & 51 & 2.0 & 40 & 2.8 & 91 & $1.40(0.93-2.11)$ \\
\hline 31 & 51 & 2.0 & 20 & 1.4 & 71 & $0.70(0.42-1.17)$ \\
\hline 33 & 20 & 0.8 & 4 & 0.3 & 24 & $0.36(0.12-1.04)$ \\
\hline 35 & 41 & 1.6 & 24 & 1.7 & 65 & $1.05(0.63-1.72)$ \\
\hline 39 & 96 & 3.8 & 49 & 3.4 & 145 & $0.91(0.65-1.28)$ \\
\hline 45 & 47 & 1.8 & 18 & 1.3 & 65 & $0.68(0.40-1.17)$ \\
\hline 51 & 158 & 6.2 & 95 & 6.7 & 253 & $1.07(0.84-1.37)$ \\
\hline 52 & 166 & 6.5 & 78 & 5.5 & 244 & $0.84(0.65-1.09)$ \\
\hline 56 & 55 & 2.2 & 20 & 1.4 & 75 & $0.65(0.39-1.08)$ \\
\hline 58 & 71 & 2.8 & 27 & 1.9 & 98 & $0.68(0.44-1.05)$ \\
\hline 59 & 131 & 5.1 & 91 & 6.4 & 222 & $1.24(0.96-1.61)$ \\
\hline 68 & 54 & 2.1 & 37 & 2.6 & 91 & $1.22(0.81-1.85)$ \\
\hline \multicolumn{7}{|c|}{ Non-oncogenic } \\
\hline 6 & 156 & 6.1 & 84 & 5.9 & 240 & $0.96(0.74-1.24)$ \\
\hline 11 & 43 & 1.7 & 11 & 0.8 & 54 & $0.46(0.24-0.88)$ \\
\hline 26 & 4 & 0.2 & 4 & 0.3 & 8 & $1.79(0.45-7.14)$ \\
\hline 40 & 54 & 2.1 & 9 & 0.6 & 63 & $0.30(0.15-0.60)$ \\
\hline 42 & 40 & 1.6 & 15 & 1.1 & 55 & $0.67(0.37-1.21)$ \\
\hline 53 & 141 & 5.5 & 86 & 6.0 & 227 & $1.09(0.84-1.41)$ \\
\hline 54 & 56 & 2.2 & 34 & 2.4 & 90 & $1.09(0.71-1.65)$ \\
\hline 55 & 64 & 2.5 & 35 & 2.5 & 99 & $0.98(0.65-1.47)$ \\
\hline 61 & 147 & 5.8 & 39 & 2.7 & 186 & $0.47(0.34-0.67)$ \\
\hline 62 & 218 & 8.6 & 102 & 7.2 & 320 & $0.84(0.67-1.05)$ \\
\hline 64 & 3 & 0.1 & 1 & 0.1 & 4 & $0.60(0.06-5.72)$ \\
\hline 66 & 124 & 4.9 & 81 & 5.7 & 205 & $1.17(0.89-1.53)$ \\
\hline 67 & 16 & 0.6 & 4 & 0.3 & 20 & $0.45(0.15-1.33)$ \\
\hline 69 & 7 & 0.3 & 1 & 0.1 & 8 & $0.26(0.03-2.07)$ \\
\hline 70 & 71 & 2.8 & 29 & 2.0 & 100 & $0.73(0.48-1.12)$ \\
\hline 71 & 53 & 2.1 & 5 & 0.4 & 58 & $0.17(0.07-0.42)$ \\
\hline 72 & 39 & 1.5 & 12 & 0.8 & 51 & $0.55(0.29-1.05)$ \\
\hline 73 & 51 & 2.0 & 22 & 1.5 & 73 & $0.77(0.47-1.27)$ \\
\hline 81 & 94 & 3.7 & 28 & 2.0 & 122 & $0.53(0.35-0.81)$ \\
\hline 82 & 18 & 0.7 & 12 & 0.8 & 30 & $1.19(0.58-2.47)$ \\
\hline 83 & 81 & 3.2 & 31 & 2.2 & 112 & $0.68(0.45-1.03)$ \\
\hline 84 & 197 & 7.7 & 119 & 8.4 & 316 & $1.08(0.87-1.34)$ \\
\hline IS39 & 20 & 0.8 & 6 & 0.4 & 26 & $0.54(0.22-1.33)$ \\
\hline CP6108 & 162 & 6.4 & 113 & 7.9 & 275 & $1.25(0.99-1.57)$ \\
\hline
\end{tabular}

NOTE. $P R$, prevalence ratio; $C l$, confidence interval. Numbers in bold correspond to statistically significant point estimates. cells. Most studies sampled only a single anatomical site or a pooled combination of a few sites for the detection of HPV. It has been suggested that sampling of the penile shaft, the coronal sulcus/glans penis, and the scrotum is necessary for optimal overall genital HPV detection [25]. In a US study, an inverse association was found between MC and HPV detection in samples from the urethra, coronal sulcus/glans penis, and penile shaft, but not in samples from the scrotum, semen, anal canal, and perianal area [33]. In another US study, the inverse association between $\mathrm{MC}$ and HPV detection was restricted to the coronal sulcus/glans penis [20]. A recently published longitudinal study conducted in the US among 477 male university students, uncircumcised men were also more likely to have HPV-positive glans and urine specimens than circumcised men, whereas circumcised men were more likely to be positive in the shaft/scrotum [34].

Taken together, results from these studies consistently show that the protective effect of MC may be restricted to infections occurring at the distal part of the penis, including the urethra, the coronal sulcus, and the glans. Since MC is limited to the removal of the foreskin, it seems unlikely that $\mathrm{MC}$ has any effect on infections occurring in the rest of the penis or the scrotum. Indeed the use in our study of an aggregate outcome that combined infections in more than one anatomical site greatly limited our ability to identify a true protective effect in specific anatomical subsites, possibly resulting in an overall underestimation of a MC protective effect.

It is interesting to note that this anatomical sitespecific pattern of HPV infections is also observed for genital warts in at least two clinical studies [35,36]. One study of men attending an STD clinic in England found that circumcised men presented genital warts more often on the shaft of the penis and less often on the glans penis than uncircumcised men [35]. Similarly, in a study of heterosexual men attending an STD clinic in Washington, circumcised men presented genital warts more often on the penile shaft whereas uncircumcised men presented genital warts more often on the glans, corona, frenulum or meatus [36]. It is clear from these clinical studies that $\mathrm{MC}$ differentially reduces the risk of genital warts in the glans as compared to the rest of the genital area. As approximately $90 \%$ of genital warts are related to HPV 6/11 infections [37], these data are consistent with our finding that $\mathrm{MC}$ is associated with a significantly reduced prevalence of HPV 11.

It is unclear why MC would be associated with a reduced detection of non-oncogenic HPV types but not of oncogenic HPV types. One possible explanation is that MC infers a weak protective effect capable of preventing only less virulent $H P V$ infections such as those caused by non-oncogenic types. Indeed, some studies provide evidence that non-oncogenic HPV types have a 
shorter persistence than oncogenic HPV types $[7,38,39]$. However, our own previous data from the HIM Study showed that the median time to clearance was not substantially different between non-oncogenic and oncogenic HPV types [40].

In this study, the distribution of the most common HPV types was not different by MC status. However, for less common types, such as HPV types $11,40,61,71$ and 81 , we did find a lower prevalence in circumcised men than in uncircumcised men. Four studies have reported on the type-specific HPV distribution by MC status $[20,32,34,41]$. In a clinical trial of $M C$ among young men in South Africa, HPV types 40, 42, 53, 70, 84, and CP6108 were found in the intention-to-treat analysis to be less frequently detected in circumcised men as compared to uncircumcised men when using urethral samples [32]. In another study of university males in Hawaii, the distribution of non-oncogenic HPV types in the coronal sulcus/glans penis did not vary by circumcision status, HPV 84 being the most common non-oncogenic type in both circumcised and uncircumcised men. However, the distribution of oncogenic HPV types did vary by MC status. Thus, while the most common oncogenic HPV types among circumcised men were types 16 and 39, those among uncircumcised men were types 66, 52, 53, and 73 [20]. Consistent with these two studies on type-specific prevalence, an RCT in Uganda found that type-specific incidence rates of HPV types 18 and 33 were lower in circumcised men than in uncircumcised men. Similarly, type-specific clearance rates for HPV types 39, 51, and 58 over a 24-month period were increased in circumcised men as compared to uncircumcised men when using samples from the coronal sulcus/glans penis [41]. Finally, in a longitudinal study of university males in Washington using samples from the penile shaft/scrotum, corona sulcus/glans, and urine, the incidence of the most common HPV types did not vary by circumcision status. The most common oncogenic HPV types at the 36-month cumulative incidence were 16,18 , and 51 , and the most common non-oncogenic HPV types were 6, 53, and 66 in both circumcised and uncircumcised men [34].

The mechanism by which circumcision might protect against HPV infection remains unclear. Removal of the foreskin could minimize the chance of acquisition of new infections or could result in an increased clearance of preexisting infections [4,42]. Additional data on HPV acquisition and clearance according to $\mathrm{MC}$ status and anatomical site are necessary to better assess the role of $\mathrm{MC}$ in the natural history of HPV infections in men.

\section{Conclusions}

In conclusion, this study shows no association between $\mathrm{MC}$ and an overall prevalence of genital HPV infections in men but MC is associated with a reduced prevalence of genital non-oncogenic HPV types. However, the lack of association with MC might be due to the analysis could not asses specific associations in the glans penis, the area expected to be most likely protected by removal of the foreskin.

\section{Abbreviations \\ HPV: Human papillomavirus; STI: Sexually transmitted infections; MC: Male circumcision; RCT: Randomized controlled trials; HIM Study: HPV in men study; CASI: Computer-Assisted Self-Interview; PRs: Prevalence ratios; Cls: Confidence intervals.}

\section{Competing interests}

G.A. My research unit is involved in vaccine trials organized by GlaxoSmithKline and Merck/Sanofi Pasteur MSD. Travel fund to conferences/ symposia/meetings are occasionally granted by either GlaxoSmithKline, Sanofi Pasteur MSD or Qiagen. A.R.G. and L.L.V. are on the speakers' bureau for Merck and are members of its advisory board. A.G.N. has received research funding from Merck \& Co. X.C. Research Grants (GlaxoSmithKline, Merck Sharp \& Dohme, Sanofi Pasteur MSD); Speakers Bureau (GlaxoSmithKline, Sanofi Pasteur MSD); Steering Committee (GlaxoSmithKline, Sanofi Pasteur MSD). F.X.B. Advisory Board (GlaxoSmithKline, Merck Sharp \& Dohme, Sanofi Pasteur MSD); Speakers Bureau (GlaxoSmithKline); Research Grants (Merck Sharp \& Dohme, Sanofi Pasteur MSD). X.C. and F.X.B. My research unit is involved in vaccine trials organized by GlaxoSmithKline and Merck/Sanofi Pasteur MSD. Travel fund to conferences/symposia/meetings and honorarium are occasionally granted by either GlaxoSmithKline, Merck, Sanofi Pasteur MSD, MTM or Qiagen. All other authors declare that they have no competing interests.

\section{Authors' contributions}

ARG, LLV, and EL were the principal investigators, conceived the study, wrote the protocols, assured funding, identified clinical investigators and study personnel, and made critical revision of the manuscript. GA was responsible for conduct analysis, interpretation of data, and drafting and revision of the manuscript. WF, and MRP made the statistical analyses, and made substantial comments to the manuscript. MA trained and supervised study clinical staff, and made substantial contributions to the manuscript. DS wrote the HPV assays protocols, performed the HPV DNA detection and genotyping of the samples validating the techniques with other referent HPV laboratories and made substantial comments to the manuscript. JS and MQ coordinated the field work in terms of study implementation and data collection, and made substantial comments to the manuscript. AGN, BL, XC, and FXB participated in the interpretation of data, and critical revision of the manuscript. All authors read and approved the final manuscript.

\section{Financial support}

This project was supported through a grant from the National Cancer Institute, National Institutes of Health [CA R01CA098803 01-A1]. The work was partially supported by the Agència de Gestió d'Ajuts Universitaris de Recerca [2009 BE-2 001444]; Instituto de Salud Carlos III [grants RCESP C03/ 09, RTICESP C03/10, RTIC RD06/0020/0095 and CIBERESP].

\section{Acknowledgements}

The authors give special thanks to the men who provided personal information and biological samples for the study. The authors would also like to thank the Digene Corporation for providing Specimen Transportation Medium for the collection and storage of samples at no charge to the study and the HIM Study team from Tampa: C. Gage, K. Eyring, N. Lambermont, E. Jolles, K. Kennedy, K. Isaacs, A. Bobanic, K. Wolf, A. Bilotto, A. Ajidahun, M. Blackmer, M. O’Keefe, B. Sirak, H. Lin, Brazil: M. L. Baggio, L. Galan, R. J. Carvalho da Silva, E. Gomes, E. Brito, F. Cernicchiaro, R. Matsuo, V. Souza, R. Cintra, R. Cunha, B. Fietzek, R. Hessel, V. Relvas, F. Silva, J. Antunes, G. Ribeiro, R. Bocalon, R. Otero, R. Terreri, S. Araujo, M. Ishibashi, the CRT- DST/AIDS Nursing team, and Mexico: A. Cruz, P. Hernandez, G. Diaz Garcia, O. Rojas Juarez, R.C. Gonzales Sosa, R. J. Alvear Vazquez, and HIM Study CoInvestigator, Johns Hopkins Ray Viscidi. 


\section{Author details}

'Unit of Infections and Cancer (UNIC), Cancer Epidemiology Research Program (CERP), Catalan Institute of Oncology (ICO), L'Hospitalet de Llobregat 08908, Barcelona, Spain. ${ }^{2}$ CIBER en Epidemiología y Salud Pública CIBERESP (Epidemiology and Public Health Biomedical Research Consortium), Barcelona, Spain. ${ }^{3}$ Program in Public Health and the Methodology of Biomedical Research, Universitat Autonoma de Barcelona (UAB). Campus Universitat Autonoma, s/n, Cerdanyola del Valles, 08193, Barcelona, Spain. ${ }^{4}$ Ludwig Institute for Cancer Research, São Paulo 01323-903, Brazil. ${ }^{5}$ Instituto Nacional de Salud Publica, Cuernavaca 62100, Mexico. ${ }^{6} \mathrm{H}$. Lee Moffitt Cancer Center and Research Institute, Tampa, FL 33612, USA. ${ }^{7}$ Instituto Mexicano del Seguro Social, Cuernavaca 62140, Mexico.

Received: 10 May 2012 Accepted: 10 January 2013

Published: 17 January 2013

\section{References}

1. Bruni L, Diaz M, Castellsague X, Ferrer E, Bosch FX, de Sanjose S: Cervical human papillomavirus prevalence in 5 continents: meta-analysis of 1 million women with normal cytological findings. J Infect Dis 2010, 202:1789-1799.

2. Smith JS, Gilbert PA, Melendy A, Rana RK, Pimenta JM: Age-specific prevalence of human papillomavirus infection in males: a global review. J Adolesc Health 2011, 48:540-552.

3. Svare El, Kjaer SK, Worm AM, Osterlind A, Meijer CI, van den Brule AJ: Risk factors for genital HPV DNA in men resemble those found in women: a study of male attendees at a Danish STD clinic. Sex Transm Infect 2002, 78:215-218.

4. Castellsague X, Bosch FX, Munoz N, Meijer CJ, Shah KV, de Sanjose S, et al: Male circumcision, penile human papillomavirus infection, and cervical cancer in female partners. N Engl J Med 2002, 346:1105-1112.

5. Baldwin SB, Wallace DR, Papenfuss MR, Abrahamsen M, Vaught LC, Giuliano AR: Condom use and other factors affecting penile human papillomavirus detection in men attending a sexually transmitted disease clinic. Sex Transm Dis 2004, 31:601-607.

6. Giuliano AR, Lazcano E, Villa LL, Flores R, Salmeron J, Lee JH, et al: Circumcision and sexual behavior: factors independently associated with human papillomavirus detection among men in the HIM study. Int J Cancer 2009, 124:1251-1257.

7. Lajous M, Mueller N, Cruz-Valdez A, Aguilar LV, Franceschi S, HernandezAvila $\mathrm{M}$, et al: Determinants of prevalence, acquisition, and persistence of human papillomavirus in healthy Mexican military men. Cancer Epidemiol Biomarkers Prev 2005, 14:1710-1716.

8. Vaccarella S, Lazcano-Ponce E, Castro-Garduno JA, Cruz-Valdez A, Diaz V, Schiavon R, et al: Prevalence and determinants of human papillomavirus infection in men attending vasectomy clinics in Mexico. Int I Cancer 2006, 119:1934-1939.

9. Lu B, Wu Y, Nielson CM, Flores R, Abrahamsen M, Papenfuss M, et al: Factors associated with acquisition and clearance of human papillomavirus infection in a cohort of US men: a prospective study. $J$ Infect Dis 2009, 199:362-371.

10. Bailey RC, Moses S, Parker CB, Agot K, Maclean I, Krieger JN, et al: Male circumcision for HIV prevention in young men in Kisumu, Kenya: a randomised controlled trial. Lancet 2007, 369:643-656.

11. Gray RH, Kigozi G, Serwadda D, Makumbi F, Watya S, Nalugoda F, et al: Male circumcision for HIV prevention in men in Rakai, Uganda: a randomised trial. Lancet 2007, 369:657-666.

12. Auvert B, Taljaard D, Lagarde E, Sobngwi-Tambekou J, Sitta R, Puren A: Randomized, controlled intervention trial of male circumcision for reduction of HIV infection risk: the ANRS 1265 Trial. PLoS Med 2005, 2:e298.

13. Auvert B, Sobngwi-Tambekou J, Cutler E, Nieuwoudt M, Lissouba P, Puren A, et al: Effect of male circumcision on the prevalence of high-risk human papillomavirus in young men: results of a randomized controlled trial conducted in Orange Farm. South Africa. J Infect Dis 2009, 199:14-19.

14. Tobian AA, Serwadda D, Quinn TC, Kigozi G, Gravitt PE, Laeyendecker O, et al: Male circumcision for the prevention of HSV-2 and HPV infections and syphilis. N Engl I Med 2009, 360:1298-1309.

15. Albero G, Castellsague X, Giuliano AR, Bosch FX: Male Circumcision and Genital Human Papillomavirus: A Systematic Review and Meta-Analysis. Sex Transm Dis 2012, 39:104-113.

16. Morris BJ, Gray RH, Castellsague X, Bosch FX, Halperin DT, Waskett JH, et al: The Strong Protective Effect of Circumcision against Cancer of the Penis. Adv Urol 2011, 201(1):812368.
17. Weaver BA, Feng Q, Holmes KK, Kiviat N, Lee SK, Meyer C, et al: Evaluation of genital sites and sampling techniques for detection of human papillomavirus DNA in men. J Infect Dis 2004, 189:677-685.

18. Shin HR, Franceschi S, Vaccarella S, Roh JW, Ju YH, Oh JK, et al: Prevalence and determinants of genital infection with papillomavirus, in female and male university students in Busan, South Korea. J Infect Dis 2004, 190:468-476.

19. Nielson CM, Harris RB, Dunne EF, Abrahamsen M, Papenfuss MR, Flores R, et al: Risk factors for anogenital human papillomavirus infection in men. J Infect Dis 2007, 196:1137-1145.

20. Hernandez BY, Wilkens LR, Zhu X, McDuffie K, Thompson P, Shvetsov YB, et al: Circumcision and human papillomavirus infection in men: a sitespecific comparison. J Infect Dis 2008, 197:787-794.

21. Partridge JM, Hughes JP, Feng Q, Winer RL, Weaver BA, Xi LF, et al: Genital human papillomavirus infection in men: incidence and risk factors in a cohort of university students. J Infect Dis 2007, 196:1128-1136.

22. Giuliano AR, Lazcano-Ponce E, Villa LL, Flores R, Salmeron J, Lee JH, et al: The human papillomavirus infection in men study: human papillomavirus prevalence and type distribution among men residing in Brazil, Mexico, and the United States. Cancer Epidemiol Biomarkers Prev 2008, 17:2036-2043.

23. Nyitray AG, Kim J, Hsu CH, Papenfuss M, Villa L, Lazcano-Ponce E, et al: Test-retest reliability of a sexual behavior interview for men residing in Brazil, Mexico, and the United States: the HPV in Men (HIM) Study. Am J Epidemiol 2009, 170:965-974.

24. Flores R, Abalos AT, Nielson CM, Abrahamsen M, Harris RB, Giuliano AR Reliability of sample collection and laboratory testing for HPV detection in men. J Virol Methods 2008, 149:136-143.

25. Giuliano AR, Nielson CM, Flores R, Dunne EF, Abrahamsen M, Papenfuss MR, et al: The optimal anatomic sites for sampling heterosexual men for human papillomavirus (HPV) detection: the HPV detection in men study. $J$ Infect Dis 2007, 196:1146-1152.

26. Gravitt PE, Peyton CL, Alessi TQ, Wheeler CM, Coutlee F, Hildesheim A, et al: Improved amplification of genital human papillomaviruses. J Clin Microbiol 2000, 38:357-361.

27. Gravitt PE, Peyton CL, Apple RJ, Wheeler CM: Genotyping of 27 human papillomavirus types by using $\mathrm{L} 1$ consensus $\mathrm{PCR}$ products by a single-hybridization, reverse line blot detection method. J Clin Microbiol 1998, 36:3020-3027

28. Bouvard V, Baan R, Straif K, Grosse Y, Secretan B, El Ghissassi F, et al: A review of human carcinogens-Part B: biological agents. Lancet Oncol 2009, 10:321-322.

29. Zou G: A modified poisson regression approach to prospective studies with binary data. Am J Epidemiol 2004, 159:702-706.

30. Spiegelman D, Hertzmark E: Easy SAS calculations for risk or prevalence ratios and differences. Am J Epidemiol 2005, 162:199-200.

31. Lu B, Viscidi RP, Wu Y, Lee JH, Nyitray AG, Villa LL, et al: Prevalent Serum Antibody Is Not a Marker of Immune Protection against Acquisition of Oncogenic HPV16 in Men. Cancer Res 2012, 72:676-685.

32. Tarnaud C, Lissouba P, Cutler E, Puren A, Taljaard D, Auvert B: Association of low-risk human papillomavirus infection with male circumcision in young men: results from a longitudinal study conducted in Orange Farm (South Africa). Infect Dis Obstet Gynecol 2011, 201(1):567408.

33. Nielson CM, Schiaffino MK, Dunne EF, Salemi JL, Giuliano AR: Associations between male anogenital human papillomavirus infection and circumcision by anatomic site sampled and lifetime number of female sex partners. J Infect Dis 2009, 199:7-13.

34. Vanbuskirk K, Winer RL, Hughes JP, Feng Q, Arima Y, Lee SK, et al: Circumcision and acquisition of human papillomavirus infection in young men. Sex Transm Dis 2011, 38:1074-1081.

35. Oriel JD: Natural history of genital warts. Br J Vener Dis 1971, 47:1-13.

36. Cook LS, Koutsky LA, Holmes KK: Clinical presentation of genital warts among circumcised and uncircumcised heterosexual men attending an urban STD clinic. Genitourin Med 1993, 69:262-264.

37. Giuliano AR, Tortolero-Luna G, Ferrer E, Burchell AN, De SS, Kjaer SK, et al: Epidemiology of human papillomavirus infection in men, cancers other than cervical and benign conditions. Vaccine 2008, 10(26):K17-K28.

38. Kjaer SK, Munk C, Winther JF, Jorgensen HO, Meijer CJ, van den Brule AJ: Acquisition and persistence of human papillomavirus infection in younger men: a prospective follow-up study among Danish soldiers. Cancer Epidemiol Biomarkers Prev 2005, 14:1528-1533. 
39. Hernandez BY, Shvetsov YB, Goodman MT, Wilkens LR, Thompson P, Zhu X, et al: Reduced clearance of penile human papillomavirus infection in uncircumcised men. J Infect Dis 2010, 201:1340-1343.

40. Giuliano AR, Lee JH, Fulp W, Villa LL, Lazcano E, Papenfuss MR, et al: Incidence and clearance of genital human papillomavirus infection in men (HIM): a cohort study. Lancet 2011, 377:932-940.

41. Gray RH, Serwadda D, Kong X, Makumbi F, Kigozi G, Gravitt PE, et al: Male circumcision decreases acquisition and increases clearance of high-risk human papillomavirus in HIV-negative men: a randomized trial in Rakai, Uganda. J Infect Dis 2010, 201:1455-1462.

42. Gray RH, Wawer MJ, Serwadda D, Kigozi G: The role of male circumcision in the prevention of human papillomavirus and HIV infection. $J$ Infect Dis 2009, 199:1-3.

doi:10.1186/1471-2334-13-18

Cite this article as: Albero et al: Male circumcision and prevalence of genital human papillomavirus infection in men: a multinational study. BMC Infectious Diseases 2013 13:18.

\section{Submit your next manuscript to BioMed Central and take full advantage of:}

- Convenient online submission

- Thorough peer review

- No space constraints or color figure charges

- Immediate publication on acceptance

- Inclusion in PubMed, CAS, Scopus and Google Scholar

- Research which is freely available for redistribution 